Int. J. Electrochem. Sci., 14 (2019) $7516-7528$

\title{
Electrochemical Oxidation of Aniline in Sodium Chloride Solution Using a $\mathrm{Ti} / \mathrm{RuO}_{2}$ Anode
}

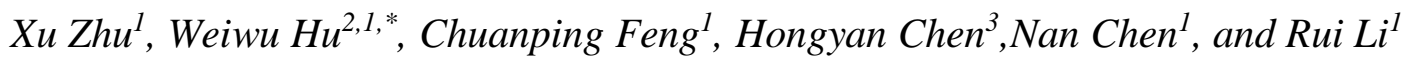 \\ ${ }^{1}$ School of Water Resources and Environment, China University of Geosciences (Beijing), No.29 \\ Xueyuan Road. Haidian District, Beijing 100083, China \\ ${ }^{2}$ The Center of Journal, China University of Geosciences (Beijing), No.29 Xueyuan Road. Haidian \\ District, Beijing 100083, China \\ ${ }^{3}$ College of Science, Beijing Forestry University, No.35 Tsinghua East Road. Haidian District, Beijing \\ 100083, China \\ *E-mail: dxqy5@cugb.edu.cn
}

doi: $10.20964 / 2019.08 .36$

Received: 5 April 2019 / Accepted: 26 May 2019 / Published: 30 June 2019

\begin{abstract}
The degradation of aniline by electrochemical oxidation process using $\mathrm{Ti} / \mathrm{RuO}_{2}$ anode has been studied under different operating conditions. Compared with the result conducted without $\mathrm{Cl}^{-}$, aniline removal rate increased sharply when using $\mathrm{NaCl}$ as the electrolyte for the electro generation of active chlorine. Researches showed that the removal rate of aniline and COD increased with the increase of $\mathrm{NaCl}$ concentration, current density, initial $\mathrm{pH}$ and plate distance. Aniline was removed completely and quickly in less than 25 min while the mineralization efficiency achieved $75.11 \%$. The result of the research showed that $\mathrm{Cl}^{-}$was an excellent agent in electrochemical oxidation degradation of aniline when using $\mathrm{Ti} / \mathrm{RuO}_{2}$ as the anode.
\end{abstract}

Keywords: Aniline, Electrochemical oxidation, $\mathrm{Ti} / \mathrm{RuO}_{2}$ anode, active chlorine

\section{FULL TEXT}

(C) 2019 The Authors. Published by ESG (www.electrochemsci.org). This article is an open access article distributed under the terms and conditions of the Creative Commons Attribution license (http://creativecommons.org/licenses/by/4.0/). 